\title{
MATRIZES DO PENSAMENTO CULTURALISTA: TOCQUEVILLE E ALMOND-VERBA
}

\section{Bruno Flávio Lontra Fagundes}

O presente trabalho supõe que uma análise mais completa do fato político deve observar o processo de agir humano dirigido a objetos, personalidades e a um sistema político entendido como prática política encarnada em atitudes e comportamentos e inscrita em sentimentos, juízos e percepções. A análise das instituições políticas na experiência societal se acresce de uma dimensão cultural que não as reduz e que se liga aos processos com que atores sociais lhes atribuem verdade e legitimidade. Analisaremos o approach culturalista presente em A democracia na América com base em formulações da Teoria da Cultura Política em The civic culture e em trabalhos posteriores que matizaram alguns conceitos explicitados em 1963, identificando semelhanças e diferenças entre o que seriam duas matrizes do pensamento culturalista em Ciência Política: a de Almond e Verba e a de Tocqueville.

Este trabalho se divide em duas partes. A primeira assinala o caráter precursor de A democracia na América em análises de Teoria da Cultura Política, fazendo rápida caracterização do contexto em que nasce o campo de estudo e em que se cristaliza a terminologia "cultura política". A segunda 
identifica alguns aspectos do que as elaborações do culturalismo tocquevilleano antecipam em termos de componentes culturais da experiência política: como discorre sobre a dimensão cultural das atividades políticas na formação da sociedade americana do século XIX, e o papel que desempenham as instituições, experimentadas na prática histórica de longa duração, para "treinar" e consolidar uma cultura política com repercussões sobre a governabilidade e a configuração da democracia americana. Procuramos apontar aspectos do que Almond e Verba viram, e não viram, da elaboração de Tocqueville em A democracia na América, a obra que entendiam como precursora do campo de análise de que foram os principais sistematizadores.

Não comungamos da idéia de que entre cultura e estruturas políticas exista uma relação de tipo causal, mas de mútua determinação. Com Soares de Lima e Cheibub, acreditamos que

"no limite, a disjuntiva desenho institucional-cultura política é irrelevante. Afinal, a cultura só tem relevância na prática política quando está inserida em instituições" (Soares de Lima e Cheibub, 1996, p. 84).

A acepção que adotamos do que sejam instituições é a de que são corpos políticos e administrativos regulares organizadores de um sistema de relações de poder - originado do e legitimado pelo - conjunto de cidadãos e incorporado no Estado como um ente a que aqueles mesmos cidadãos requerem direitos e prestam deveres regulares como condição de seu convívio político e societal cotidiano. Por mais que tantas relações de poder, também políticas, não se manifestem pela ação do e em direção ao Estado. Aqui se valoriza a obra pioneira de Almond e Verba e seu legado: um campo de análise proposto em dado contexto histórico que foi capaz de forjar uma tradição de estudos na Ciência Política. 
Eventualmente, aqui não nos restringimos a Almond e Verba, mas ainda a textos que reforçam a tradição analítica fundada por aqueles autores, já que sua obra não escapa de apropriações diversas posteriores, que, a favor ou contrárias, analistas fizeram dela ao longo do tempo e que marcam, também para nós, a percepção que temos dela ${ }^{1}$.

\section{O culturalismo precursor de $\boldsymbol{A}$ democracia na América}

De certa forma, compreender o viés culturalista tocquevilleano é, antes, compreender a motivação culturalista dos que atribuíram como de cultura política o relato de Tocqueville em A democracia na América. Significa buscar as razões que encontraram Almond e Verba para caracterizar o processo histórico mundial do Pós-II Guerra tal como caracterizaram, no qual agiam duas realidades: a complexificação dos sistemas políticos na história mundial - no qual "a mudança cultural adquiriu um novo significado" - e a renovação da Ciência Política americana. Para os autores, o impacto na ordem mundial provocado pelos nacionalismos emergentes na Ásia, África e Oriente Médio - de onde se revelam culturas e instituições sociais e políticas variadas - com a criação de áreas de influência ideológica, acompanhando o advento do sufrágio universal, dos partidos e meios de comuni-

\footnotetext{
${ }^{1}$ Existem variações do pensamento culturalista dentro da Ciência Política que refazem alguns termos de Almond e Verba. Ruth Lane entende que a cultura política é válida se questiona os modelos de decisão formal baseados em teorias da escolha racional que não capturam os objetivos (the goals) existentes de fato quando os indivíduos tomam decisões na política. "[...] rational-choice models do not [...] constitute a general model because they have no systematic way to discover, to define, or to incorporate these multiple goals" (Lane, 1992, p. 364). Numa menção mais explícita à obra de Almond e Verba, Lane afirma que "political culture is not a static conceptual cage for classifying nations, but contains living principles that constantly interact in the political marketplace of daily political life" (Lane, 1992, p. 375). Aqui, reiteramos o diagnóstico que a própria autora faz sobre o que considera as obras fundadoras da Teoria da Cultura Política, The civic culture (Almond e Verba) e Political culture and political development (Pye e Verba): "all revolutionary in their day": a falta não está nelas, mas entre os que se apropriaram delas depois, os sucessores, "who have failed to improve on what they inherited" (Lane, 1992, p. 364).
} 
cação de massa e do reforço da articulação de grupos de interesse politicamente influentes, teria complexificado os sistemas políticos, exigindo da Ciência Política "teorias políticas mais adequadas" (Almond e Powell, 1972, p. 9).

"Os eventos desde a II Guerra Mundial ergueram questões do futuro da democracia em escala mundial. As 'explosões nacionais' na Ásia e África e a quase universal pressão por povos antes isolados e sujeitados por admissão no mundo moderno põem mais esta questão política especial do futuro caráter da cultura mundial em um contexto maior. A mudança cultural adquiriu um novo significado na história do mundo. [...] A questão central da política pública na próxima década é que conteúdo terá esta emergente cultura mundial" (Almond e Verba, 1965, p. 1-2²).

Para os autores, o que pode decorrer dessas "explosões 134 nacionais" é uma incógnita, mas, certamente, uma "emergente cultura mundial”, naquele instante, estaria marcada por um traço acentuadamente participativo, em que sistemas políticos estão, basicamente, entre as alternativas de democracia ou totalitarismo. Os autores crêem que instituições democráticas não bastam, desde que também é necessária uma "cultura política consistente com a democracia". Este é o desafio, visto que a transferência de "cultura política dos estados democráticos ocidentais para as nações emergentes encontra sérias dificuldades" (Almond e Verba, 1965, p. 5). Preocupados com a estabilidade democrática, indicam que sujeitos sociais estão entrando naquela "emergente cultura

\footnotetext{
2 "The events since World War II have raised questions of the future of democracy on a world scale. The "national explosions" in Asia and Africa and the almost universal pressure by previously subjected and isolated peoples for admission into the modern world put this more special political question into the broader context of the future character of the world's culture. Culture change has acquired a new significance $[\ldots]$ The central question of public policy in the next decades is what content this emerging world culture will have."
} 
mundial" com uma noção tecnocrática da política e com elementos tradicionais de suas culturas de origem.

Num ambiente que modifica o mundo e os termos de uma dada estrutura intelectual de percepção das realidades, era hora de a Ciência Política oferecer um "exemplo mais amplo da experiência do homem com instituições e processos políticos" (Almond e Powell, 1972, p. 9). A incorporação de novas perspectivas de análise no contexto da publicação de The Civic Culture, em 1963, seria uma espécie de débito intelectual a pagar com métodos e teorias das Ciências Sociais, de que o "estudo dos sistemas políticos estrangeiros" no campo da Política Comparativa já vinha sendo influenciado nos Estados Unidos desde o início dos anos 1950. "Experiências teóricas estão introduzindo novos conceitos, como cultura política, papel político e socialização política baseados nas Ciências Sociais - o estudo da vida social como um todo - na Psicologia e na Antropologia - o estudo do homem e da sua cultura (Almond e Powell, 1972, p. 12).

É nas linhas gerais desse contexto de rearranjo político global que ressurge a idéia da atuação da variável cultural na política, e dizemos "ressurge" porque essa idéia já estaria presente na tradição de pensamento sobre a política desde Platão e Aristóteles, sem ter sido nomeada assim, no entanto. De modo pioneiro, The civic culture distingue e nomeia, num corpus teórico, o que já existiria antes, e que, sem estar devidamente institucionalizado, não constitui um campo com terminologia e categorias sistematizadas próprias de análise $^{3}$. Nunca devidamente identificada dentro da Ciên-

\footnotetext{
${ }^{3}$ Importa destacar o que Almond, numa de suas definições do campo, afirma sobre a Cultura Política: "Political Culture is not a theory: it refers to a set of variables which may be used in the construction of theories", e que "imputes some explanatory power to the psychological or subjective dimensions of politics, just as it implies that there are contextual and internal variables which may explain it" (Almond, 1989 p. 26). Aqui, estamos nos apropriando da obra de Almond e Verba como corpus teórico que permite fazer proposições pragmáticas sobre a relação en-
} 
cia Política como um campo de conhecimento específico, capaz de gerar, como gerou posteriormente, toda uma linha de análise que dialoga com disciplinas afins para a análise do fato político, a Teoria da Cultura Política por Almond e Verba vai disponibilizar um instrumental conceitual de cujo cerne vão surgir as leituras de A democracia na América como uma obra que indica em Ciência Política o culturalismo precursor de Tocqueville, tal como destacado, primeiro por Almond e Verba - tendo em vista o mesmo foco de análise de The civic culture e A democracia na América: a democracia - e depois destacado por muitos outros autores que reconheceram, ou mesmo se filiaram, uns mais outros menos, à cultura política como perspectiva de análise. É importante reconhecer como a obra de Tocqueville é apropriada por Almond e Verba a ponto de sugerir-lhes a matriz para a constituição de todo um campo de análise mais de cem anos depois; e mesmo identificar uma espécie de leitura segunda, aquela que outros auto136 res fizeram da apropriação que Almond e Verba fizeram de Tocqueville. Esse procedimento permite-nos, talvez, alcançar pontos de fuga e de aproximação entre o pensamento culturalista dos autores que estamos analisando.

Almond destaca a influência de Rousseau sobre Tocqueville no que diz respeito à importância da socialização e da cultura políticas na forma da política e da legislação pública das nações, ao realçar que "a análise de Tocqueville da democracia americana e das origens da Revolução Francesa está entre os mais sofisticados tratamentos destes temas" (Almond, 1989, p. 5-6 $)^{4}$. O tratamento tocquevilleano dos "costumes" do povo para a análise da estabilidade da república democrática é destacado por Almond. Para ele, Tocqueville alarga a idéia de costumes de um povo, entendendo as atitudes ligadas não

tre cultura política e desempenho institucional, atestado pela tradição de análise crítica que deram forma e que suscita tantas controvérsias.

4 "Tocqueville's analysis of American democracy and of the origins of the French Revolution are among the most sophisticated treatments of these themes". 
apenas a modos de sentir-agir - os hábitos do coração - , mas a uma dimensão intelectual e moral-valorativa que fará parte do receituário nocional da Cultura Política. Os costumes seriam, seguindo o raciocínio tocquevilleano, também hábitos da mente, modos de pensar-agir ligados "a várias noções e opiniões correntes entre os homens e a massa daquelas idéias que constituem a característica de sua mente" (Almond, 1989, p. 6) ${ }^{5}$. Examinando A democracia na América, Almond percebe que fatos observáveis deitam raízes numa instância cultural da relação dos homens com a política ainda não devidamente enquadrada em teoria.

Muitos autores confirmam o culturalismo de $A$ democracia na América e seria ocioso nos estendermos aqui. Rennó sugere, de uma baliza temporal, o argumento que requalifica a análise empreendida por Almond e Verba: numa perspectiva contemporânea, o estudo da cultura política nasceu "apenas nos anos 1960”, mesmo que Tocqueville já estivesse tratando da variável cultural quase um século antes. Rennó aponta que o ambiente histórico no qual a obra de Almond e Verba surge é marcado pela "desilusão com as expectativas iluministas e liberais" e "o avanço de técnicas de pesquisa e abordagens metodológicas" (Rennó, 1998, p. 71). Se consideramos a historicidade de qualquer conceito, este fato matiza algo do que aproxima Almond e Verba de Tocqueville - o fato de construírem seus conceitos numa situação comparativa - e do que os afasta, à medida que as exigências de uma época pragmática não estavam postas para Tocqueville, imbuído da premissa iluminista do aperfeiçoamento dos indivíduos e dos povos no tempo.

\section{Os comparativismos de Tocqueville e de Almond-Verba}

Vemos o quanto a baliza analítica de Tocqueville está posta já no início da obra quando compara a França e a Nova

\footnotetext{
5 "To the various notions and opinions current among men and to the mass of those ideas which constitute their character of mind."
} 
Inglaterra ${ }^{6}$. As histórias pareciam inscritas no mesmo processo rumo à democracia, mas havia especificidades. Na América, as condições iguais promoveram o ambiente adequado em que, transplantado pelos imigrantes europeus, o princípio democrático cresceu isolado de "outros contra os quais lutava" na Europa: "Aí pôde crescer em liberdade e, adequando-se aos costumes, desenvolver-se pacificamente nas leis", afirma Tocqueville. Na França, as relações políticas que se seguiram à revolução não conseguiram estabelecer relações de poder aceitas como legítimas. Tocqueville sugere que a análise dos processos políticos deve contemplar uma consideração perceptiva da parte dos homens. No Ancien Régime, mesmo considerando a desigualdade e as misérias da ordem feudal, "as almas não se tinham degradado" e os atores sociais aceitavam como legítimo o estado de coisas em que viviam, porque:

"não é o uso do poder nem o hábito da obediência o que deprava os homens; é o uso do poder que eles consideram ilegítimo, e a obediência à autoridade vista como usurpada e opressora [...]".

Já Almond e Verba, forçando um pouco, comparam todas as nações aos olhos da experiência histórica ocidental. Contradizem a teoria da modernização que prega o desenvolvimento natural de desenhos político-institucionais democráticos em sociedades modernizadas e industrializadas, advertindo sobre as experiências totalitárias. Um dos fatores que deve ser analisado como fundamento da legitimidade política requerida para o desenvolvimento de instituições democráticas é a cultura política internalizada nas pessoas, onde, por processos interpretativos de conferência

\footnotetext{
${ }^{6}$ Neste trabalho, os trechos em aspas sobre Tocqueville foram retirados de $A d e$ mocracia na América. Alguns foram usados apenas para compor esse texto, motivo pelo qual não foram localizadas as páginas em que estão na obra.
} 
de sentido, vetores valorativos, afetivos e cognitivos jogam com motivos e sentimentos de aceitação e adesão aos formatos institucionais propostos às pessoas. Aqui, focaremos três aspectos que nos parecem subjacentes às respectivas interpretações culturalistas de Almond e Verba e Tocqueville, sublinhando o que a leitura de suas obras pode iluminar uma a outra, e as demais que militam no campo da análise da Cultura Política.

\section{A concepção de história e tempo}

Almond e Verba estão atentos ao processo histórico de modo diferente do de Tocqueville. Ao discorrer sobre as new nations, alegam que elas estão procurando como fazer "num breve período de tempo o que tomou séculos para se consumar no Ocidente". E indagam: "é possível encontrar substitutos para este gradual e lento processo de mudança política?" (Almond e Verba, 1965, p. 370) ${ }^{7}$. Seguindo os autores, a história atingira seu termo final - a cultura cívica da democracia americana, enquanto, para Tocqueville, a história ainda se processava e a cultura política democrática, que via se cristalizar na Nova Inglaterra, contava com o contraste de uma possível forma democrática alterada que podia nascer da experiência histórica francesa.

Para Almond e Verba, a "cultura cívica” é o princípio de que parte a análise e padrão ótimo a que devem chegar as novas nações, para o que tem o aval da democracia americana posta à prova pela história. No esquema conceitual dos autores, a democracia americana é uma espécie de protótipo, fim último e parâmetro pelo qual se verifica a natureza de qualquer sistema político, se mede sua distância do protótipo, reificando-o, e pelo qual são corrigidas as estruturas políticas de cada país. A cultura política de Almond e Verba

\footnotetext{
7 "Is it possible to find substitutes for this gradual and fusional process of political change?."
} 
carece de cultura, no sentido de que toda cultura se cristaliza por uma história. Se a experiência histórica de observar sistemas políticos emergentes serve-lhes para avaliar sua variedade, também serve-lhes para apurar "o que falta" para chegar ao ideal, e nunca "o que existe" a partir do que se podem constituir variadas formas de experiência democrática. Gómez diz sobre The Civic Culture:

“[...] penetra pouco na bagagem de significados, tradições e instituições políticas que todo povo constrói, mantém e modifica ao longo de sua história. Certamente, o estudo destes fatores constitui um programa de investigação distinto, posto que implica abordar a cultura política de uma perspectiva que trata de interpretar os significados e códigos próprios, e às vezes exclusivos de cada sociedade, sem cujo conhecimento é difícil de entender as conseqüentes atitudes políticas [...]" (Gómez, 2004, p. 27 - grifo nosso)

Se, em ambos os pensamentos, é no tempo e na história em que uma cultura política se constitui, há uma distinção essencial: para Tocqueville, o tempo não pode ser reposto a não ser pelo próprio tempo; assim, experimentando novas formas de convívio, os homens "treinariam" a democracia naturalmente para que ela ganhasse raízes. Quando sugere aos franceses encontrar "ensinamentos de que possamos tirar proveitos", Tocqueville sabe que o processo da história está em andamento, e que, estando a Nova Inglaterra e a França numa mesma "revolução social”, algumas correções de rumo poderiam alterar o desenrolar dos acontecimentos ao modo como via idealmente na colônia inglesa. Mas sempre num mesmo curso da história a que ambos os territórios estavam submetidos. Para Almond e Verba, ao contrário, senão o tempo, pelo menos seus resultados são passíveis de serem instrumentalizados: "o mais óbvio substituto para o tempo seria a 
educação" (Almond e Verba, 1965, p. 370) ${ }^{8}$, ou seja, de alguma forma a educação poderia forjar uma cultura política que o tempo e as circunstâncias históricas não o fizeram - e num ritmo diferente do que seria se tivesse deixado para ser feito pelo curso natural do passar dos anos - embora os autores desconfiem de que a "educação formal não pode substituir adequadamente o tempo na criação destes outros componentes da cultura cívica" (Almond e Verba, 1965, p. 371) ${ }^{9}$. Almond e Verba parecem valorizar a busca de alternativas viáveis que condensem em poucos muitos anos de história.

Essa compreensão é importante se compararmos os dois pensamentos culturalistas, já que nos conduz a um aspecto da variável cultural na política que não pode ser negligenciado: a capacidade de uma cultura política reter ou não ensinamentos em direção a instituições políticas através do tempo artificial da escola e de instituições que não são estritamente políticas. Fazendo um pequeno jogo de palavras, para Tocqueville a escola primeira e mais fundamental era a escola da vida, agente poderoso de socialização, no qual, diariamente, os americanos construíam, e viviam, suas instituições numa espécie de tempo natural capaz de cristalizar uma duração que só o passar dos anos pode fazer. Para Almond e Verba, preocupados com o destino democrático das novas nações em um tempo curto, era preciso identificar, primeiro, o papel precípuo da escola formal para ensinar conteúdos que induzem às atitudes, e, segundo, certificar-se de que ela poderia fazê-lo pelo tempo artificial.

\begin{abstract}
"Nossos dados têm mostrado a educação ser o mais importante determinante das atitudes políticas; e também o mais manipulável. A grande vantagem da educação é que
\end{abstract}

\footnotetext{
8 "The most obvious substitute for time would be education."

9 "Formal education may not adequately substitute for time in the creation of these other componentes of the civic culture."
} 
habilidades que podem levar anos para desenvolver pela primeira vez podem ser transmitidas muito mais facilmente sempre que haja alguém que as transmita" (Almond e Verba, 1965 , p. 370$)^{10}$.

Parece-nos que há uma diferença de receita em função de diagnósticos diferentes que são feitos. E, mais uma vez, o tempo histórico pode ser um bom parâmetro para julgar das análises que Almond e Verba e Tocqueville fazem da variável tempo no processo de mudança e/ou permanência cultural. Os dois pensamentos culturalistas têm a marca de sua época. A análise desse ponto pode ajudar-nos a pensar em que medida é possível predizer mudanças na relação entre estruturas políticas e indivíduos manipulando aspectos e traços de sua cultura política sem que elas sejam acompanhadas de mudanças nas práticas institucionais.

\section{$142 \mathbf{O}$ padrão médio das condições de participação}

Tanto Tocqueville como Almond e Verba estabelecem uma relação entre a eficiência da democracia e uma distribuição média das oportunidades e das condições de participação, mas há que se matizar o ponto a que cada um se refere. Em Almond e Verba, a média corresponde a uma quantidade balanceada de componentes psicoculturais das culturas paroquial, súdita e participante em cada um dos indivíduos, de forma que vontade e ação efetiva não sejam nem escassas nem exageradas; assim como a média se refere a uma distribuição equânime, no seio da população, entre indivíduos mais apáticos e outros tantos mais participativos, de forma que um grau de participação garanta sempre ao sistema político a existência de uma esfera pública balanceada

\footnotetext{
10 "Our data have shown education to be most important determinant of political attitudes; and it is also the most manipulatable. The great advantage of education is that skills that may take years to develop for the first time can be passed on much more easily once there are some who posses them."
} 
entre inputs e outputs ao sistema político, entre ação efetiva e potencial dos cidadãos e das personalidades políticas. Já Tocqueville leva o padrão médio a uma análise que desdobra um dado quantitativo num valor, qualificando-o como uma variável cultural explicativa da política de forma diferente da de Almond e Verba. As elaborações de Tocqueville a partir do que via os americanos experimentar no trato com aquilo que era de seu comum interesse conduzem-lhe a uma formulação culturalista que, parece-nos, desenvolve melhor o dispositivo de enraizamento da cultura nas e pelas instituições políticas, reforçando a mensagem de que a política depende de fatores culturais.

$\mathrm{Na}$ argumentação tocquevilleana, um padrão médio das condições de participação contém um elemento mental - simbólico, diríamos também - importante: ele vai ao plano de uma média das inteligências, o que é fundamental levando-se em conta o papel decisivo do debate livre - sem constrangimentos de qualquer tipo - para o desempenho das democracias, o que sugere uma crítica de concepções aristocráticas da cultura. Para Tocqueville, o exercício cotidiano da política e da discussão socializou os indivíduos, com o que se constituiu a grande escola do debate ao vivo e não-artificial. $\mathrm{Na}$ América, as inteligências mesmas são niveladas, não só a riqueza. A política americana é assunto e exercício de todos, para o que contribui o fato de que não há ninguém intelectualmente superior que tenha qualquer credencial alheia aos demais cidadãos de apreciação elevada de seus argumentos ou opiniões na arena política. Para Tocqueville, o processo de decisão entre os cidadãos na Nova Inglaterra não preservou o elemento hierárquico que "classificava despoticamente os homens na mãe-pátria” e de cuja ausência:

"a colônia apresentava, cada vez mais, o espetáculo novo de uma sociedade homogênea em todas as suas partes. [...] Não creio que haja país no mundo em que, 
proporcionalmente à população, se encontrem tão poucos ignorantes e menos sábios do que na América. A instrução primária está ao alcance de todos; a educação superior não está ao alcance de quase ninguém. Isso é facilmente compreensível, e, de certa forma, é o resultado do que dissemos acima [...] Na América há poucos ricos; quase todos os americanos precisam exercer uma profissão. Ora, toda profissão exige aprendizado. Os americanos só podem, portanto, dar os primeiros anos da vida ao cultivo geral da inteligência; com quinze anos entram para uma carreira; assim, sua educação acaba frequentemente, na época em que começa a nossa. Se prossegue, dirige-se apenas a uma matéria especial e lucrativa; estuda-se uma ciência como se exerce uma profissão; retém-se dela as aplicações de utilidade atual reconhecida [...]. Não existe, portanto, na América, classe em que a inclinação para os prazeres intelectuais se transmita com familiaridade 144 e disponibilidade hereditárias e que tenha os trabalhos da inteligência em grande estima [...] estabeleceu-se, na América, nos conhecimentos humanos, certo nível mediano. Todos os espíritos aproximaram-se desse nível, uns abaixando-se, outros elevando-se [...]" (Tocqueville, 1973, pp. 196 e 200)

\section{0 papel dos símbolos}

Nem Almond e Verba, nem Tocqueville discorrem sobre os processos de legitimação que se encarnam em símbolos da comunidade política agregada. Almond e Verba fazem uma menção explícita, sem maior desenvolvimento, ao papel dos símbolos como componentes de uma cultura política, e Tocqueville não o faz nem explicitamente. Ao discorrer sobre a escola como canal de socialização política, Almond e Verba acreditam que ela ensina habilidades, informações comuns, o contato com os mass media, os conteúdos específicos relativos a estruturas da política formal 
e a importância das instituições políticas. No entanto, têm dúvida se a escola ensina "atitudes sociais fundamentais"11, para o que convocam o papel a ser assumido por outros canais, como a família, associações voluntárias e de trabalho. Mesmo assim, a importância de outros canais de participação "na criação de confiança social e compromisso afetivo com o sistema politico é questionável" (Almond e Verba, 1965, p. 371) ${ }^{12}$. Para eles, um senso de identidade política comum implica:

"[um] compromisso afetivo comum ao sistema político, assim como um senso de identidade de uns cidadãos com os outros [já que] participação e habilidades cognitivas não são suficientes para criar uma comunidade política na qual alguém confia e pode cooperar com outros cidadãos, e onde o apego de alguém ao sistema político é profundo e afetivo" (Almond e Verba, 1965, p. 371) ${ }^{13}$.

Ao comparar México e Alemanha, Almond e Verba indicam um fator que os diferencia. A cultura política alemã contém alto grau de cognição e conhecimento político, com componentes fortes aprendidos no processo de educação escolar, mas lhe falta o que sobra na cultura política mexicana: um sistema de afeto e um senso altamente desenvolvido de identidade, o que vem acompanhado por "um senso de habilidade para cooperar politicamente ou pelo menos a aspiração para tal cooperação" (Almond e Verba,

\footnotetext{
11 "Underlying social attitudes", nas palavras dos autores.

12 "In the creation of social trust and affective commitment to the system is more questionable."

13 "An identity that implies common affective commitment to the political system, as well as a sense of identity with one's fellow citizens.Participation and cognitive skills are not enough to create a political community in which one trusts and can cooperate politically with one's fellow citizens, and in which one's attachment to the political system is deep and affective."
} 
1965 , p. 372) ${ }^{14}$. E isso porque o México teve um "evento simbólico agregador", a Revolução Mexicana, que teria criado um sentido de identidade e compromisso com o sistema político que "permeia quase todos os estratos sociais da sociedade”. Dizem que:

“se uma nova nação está para criar uma cultura cívica, são necessários tanto os símbolos unificadores e um sistema de afeto que a Revolução Mexicana proveu como também as habilidades cognitivas que existem na Alemanha" (Almond e Verba, 1965, p. 372) ${ }^{15}$.

Almond e Verba indicam que símbolos nacionais se inscrevem fortemente para fortalecer a orientação afetiva que cria o apego ao sistema político como um todo. Os autores estiveram atentos ao poder simbólico de certos acontecimentos, mas a eficácia simbólica está enfraquecida por146 que perdida em meio a outras orientações e acontecimentos com que os símbolos se igualam perdendo sua eficácia propriamente de símbolo. Almond e Verba se utilizam do símbolo como um índice de solidariedade social a mais no conjunto de elementos que organizam as orientações dos cidadãos em direção à política, tendo a história como lastro de passado comum. A Revolução Mexicana, para os mexicanos, é um dado comparativo que, apesar de positivo, ainda está em falta no conjunto de orientações que assemelharia a cultura política mexicana à cultura cívica de democracia. Os autores sugerem que a Revolução Mexicana é mais que uma orientação: é um fato simbólico convencionado de que qualquer cultura política não pode prescindir.

\footnotetext{
14 "By a sense of ability to cooperate politically - or at least the aspiration for such cooperation."

15 "If a new nation is to create a civic culture, it needs both the unifying symbols ans system affect that the Mexican Revolution has provided, as well as the cognitive skills that exist in Germany [...]."
} 
Numa época em que ainda não tem a terminologia, Tocqueville parece estar falando de símbolo, mesmo que não o nomeie. Não é improvável que assim o fizesse se, no século XIX, pudesse recorrer a terminologias e conceitos de uma Ciência Antropológica vizinha. Para o autor, a acepção de "símbolo" avança no sentido de que não é apenas um indicador, mas um fator de aperfeiçoamento de práticas institucionais, já que símbolos catalisam um conjunto de agentes e forças dispersas em nome de uma causa partilhada. Porque, nos termos com que pensamos, hoje, os processos de cristalização de princípios de organização de comunidades políticas, é possível afirmar que, mesmo sem nomear, Tocqueville esteve atento aos processos de simbolização constituidores de culturas políticas. A soberania popular se manifesta como força simbólica identificada a um princípio que "reina sobre o mundo político americano como Deus sobre o universo". Para ele, a soberania popular cotidianamente exercida pelos americanos transforma uma prática num princípio de caráter sagrado, simbolizando o que passa a ser percebido como um valor do conjunto dos cidadãos e a nenhum em particular. Nos Estados Unidos, o "povo" encontra sua força constitutiva numa dimensão divina que enraíza hábitos, costumes e valores numa cultura política exemplar.

“[...] O povo participa da composição das leis, através da escolha dos legisladores, e de sua aplicação, pela escolha dos agentes do Poder Executivo; pode-se dizer que governa diretamente, tanto é fraca e restrita a parte que toca à administração, tanto essa se ressente de sua origem popular e obedece ao poder de que emana. O povo reina sobre o mundo político americano como Deus sobre o universo. É a causa e o fim de todas as coisas; tudo dele sai e nele se absorve" (Tocqueville, 1973, p. 202) 
Por fim, entendemos que as reflexões de Almond e Verba e Tocqueville se assemelham e se diferenciam no que toca ao lugar em que abordam o mundo político. Se, para uns, está em jogo um projeto de renovação científica, para outro está o molde para os relatos de caráter etnográfico que vão marcar, mesmo que não o saiba, a segunda metade do século XIX e a primeira do XX. Almond e Verba estão escrevendo num lugar de instituição científica, o de uma Ciência Política que reconhece o Estado e suas instituições como fundamentos ontológicos condicionadores de critérios de avaliação, resultados e objetos do que seria o "propriamente político". Tocqueville não está num lugar de ciência, o que lhe favorece outro modo de indagar a política dos povos. Este fato pode condicionar uma percepção do conhecimento em que cabe fazer afirmações sobre as coisas sem que elas sejam provadas ou se manifestem de forma irrefutável. Se o conhecimento de Ciência Política de Almond e Verba é científico, tout court,

148 para Tocqueville as observações não estão sob as exigências de métodos e procedimentos observáveis e demonstráveis. Nessa perspectiva, podemos marcar um ponto que unifica as reflexões de Almond e Verba e Tocqueville: o de que, recolhendo resultados sobre o político, condicionados pela natureza de suas indagações, suas abordagens reforçam os fatores e variáveis nem sempre quantificáveis dos comportamentos e das práticas políticas, o que confere ao político uma dose de imponderável que o coloca entre a crença e o conhecimento. Talvez isso não seja tão mau, e, provavelmente, essa era uma convicção sobre o próprio do político partilhada pelas matrizes dos pensamentos culturalistas analisados aqui, o que as transforma no que seria o campo da Cultura Política como o concebemos ao longo desse trabalho.

\section{Bruno Flávio Lontra Fagundes}

é doutorando do Programa de Pós-graduação em História da Universidade Federal de Minas Gerais (UFMG) 


\section{Bibliografia}

ALMOND, G. A. 1989. "The intellectual history of the civic culture concept”. In: ALMOND, G. A.; VERBA, S. (orgs.). The civic culture revisited. New York/London/New Delhi: Sage Publications, pp. 1-35.

1990. "The study of political culture". In: A discipline divided. Schools and sects in political science. London/New Delhi: Newbury Park/Sage Publications, pp. 138-156.

; POWELL, G. B. 1972. Uma teoria de política comparada. Rio de Janeiro: Zahar.

; VERBA, S. 1965. The civic culture. Political attitudes and democracy in five nations. USA/Canadá: Little, Brown and Company.

ECKSTEIN, H. 1990. "Political culture and change". American Political Science Review, vol. 84, p. 254.

GÓMEZ, L. H. 2004. "Cultura política y democratización en América Latina”. Revista de Ciencias Sociales, Universidad de Costa Rica, $\mathrm{n}^{\circ}$ 103104, pp. 23-37.

HARRISON, L.; HUNTINGTON, S. (orgs.). 2002. Cultura importa: os valores que definem o progresso humano. Rio de Janeiro: Record.

INGLEHART, R. 2002. "Cultura e democracia”. In: HARRISON, L.; HUNTINGTON, S. (orgs.). Cultura importa: os valores que definem o progresso humano. Rio de Janeiro: Record, pp. 133-153.

JOHNSON, J. 2004. "Problemas conceituais como obstáculos ao progresso em ciência política. Quatro décadas de pesquisa em cultura política”. In: Teoria e Sociedade. Revista dos departamentos de Ciência Política e de Sociologia e Antropologia da UFMG, n 121, pp. 128-163, janeiro-junho.

LANE, R. 1992. "Political culture: residual category or general theory?" Comparative Political Studies, vol. 25, n 3, pp. 362-387, outubro.

PATEMAN, C. 1992. "O sentido de eficácia política e a participação no local de trabalho". In: Participação e teoria democrática. Rio de Janeiro: Paz e Terra, pp. 65-91.

PUTNAM, R. D. 1996. Comunidade e democracia: a experiência da Itália moderna. Rio de Janeiro: Ed. FGV.

RENNÓ, L. 1998. "Teoria da cultura política: vícios e virtudes”. BIB Revista Brasileira de Informação Bibliográfica em Ciências Sociais, Rio de Janeiro, $\mathrm{n}^{\circ} 45$, pp.71-92, $1^{\circ}$ semestre.

SOARES DE LIMA, M. R.; CHEIBUB, Z. B. 1996. "Instituições e valores. As dimensões da democracia na visão da elite brasileira”. Revista Brasileira de Ciências Sociais, $\mathrm{n}^{\circ}$ 31, ano 11, pp. 83-110, junho.

STREET, J. 1994. "Political culture - From civic culture to mass culture". 
Matrizes do pensamento culturalista: Tocqueville e Almond-Verba

British Journal of Political Science, vol. 24, n 1, pp. 95-114, janeiro.

TOCQUEVILLE, A. de. 1973. "A democracia na América”. In: Federalistas.

São Paulo: Abril Cultural, pp. 185-285. (Coleção Os Pensadores, 29.) 


\section{MATRIZES DO PENSAMENTO CULTURALISTA: TOCQUEVILLE E ALMOND-VERBA}

BRUNO FLÁVIO LONTRA FAGUNDES

Este artigo analisa o approach culturalista em A democracia na América, com base em alguns itens de Teoria da Cultura Política feitas em The civic culture, e em trabalhos posteriores que matizaram alguns de seus conceitos, marcando semelhanças e diferenças entre o que seriam duas matrizes do pensamento culturalista em Ciência Política: a de Almond e Verba e a de Tocqueville.

Palavras-chave: Culturalismo; Tocqueville; Almond-Verba.

MATRICES OF CULTURALIST THOUGHT: TOCQUEVILLE AND ALMOND-VERBA

This article analyzes the culturalist approach in The democracy in America, based on some itens of the theory found in The civic culture, and in posterior works that have enhanced some of its concepts, marking similarities and differences between what could be called the two matrices of the culturalism in Political Science: Almond and Verba's and Tocqueville's. 
Keywords:Culturalism; Tocqueville; Almond-Verba. 